Plant Tissue Cult. \& Biotech. 25(1): 99-102, 2015 (June)

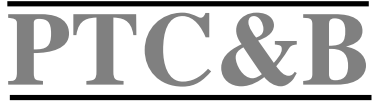

\title{
Effect of 5-aminolevulinic Acid on PLB Culture of Cymbidium dayanum In Vitro
}

\section{Syeda Jabun Nahar', Syed Mostafizul Haque and Shimasaki Kazuhiko}

Faculty of Agriculture, Kochi University, Nankoku, Kochi 783-8502, Japan

Key words: ALA, Organogenesis, Plant growth regulator, Protocorm-like body

5-aminolevulinic acid (5-ALA) has been suggested to be a new natural and environmental friendly regulator, which can be widely used in agriculture. The present study was undertaken to investigate the effect of 5-aminolevulinic acid on organogenesis of Cymbidium dayanum in vitro under white fluorescent tube. PLBs of Cymbidium dayanum were cultured on the modified MS supplemented with 5-ALA at various concentrations $(0,0.1,1$ and $10 \mathrm{mg} / \mathrm{l})$. The addition of 5ALA in the growth media, showed that $1 \mathrm{mg} / \mathrm{l}$ of 5-ALA significantly enhanced the formation of PLB (87\%), shoot (73\%) and root (47\%) to the maximum within 50 days of culture; whereas in the control formation of PLB, shoot and root was the lowest. The result of the present study shown clearly that 5-ALA added to the culture media, acts as a plant growth stimulator to induce PLB, shoot- and root formation of Cymbidium dayanum.

Plant growth regulators (PGRs) are organic compounds, other than nutrients, that modify plant physiological processes. PGRs, called biostimulants or bioinhibitors, act inside plant cells to stimulate or inhibit specific enzymes or enzyme systems and help regulate plant metabolism. Aminolevulinic acid (5ALA) is a key precursor in the biosynthesis of porphyrins such as chlorophyll and heme. ALA has been suggested to be a new natural and environmental friendly regulator, which can be widely used in agriculture (Wang et al. 2004). ALA application increased the yield of garlic, barely, rice and potato plants by significantly enhancing their photosynthetic capacity and plant biomass (Tanaka et al. 1992). Recently, ALA has been shown to be involved in PLB culture of Cymbidium insigne and Cymbidium finlaysonianum (Nahar and Shimasaki 2014). There are several reports on tissue culture of different species of Cymbidium orchids but the organogenesis of $C$. dayanum has been very less documented in

${ }^{1}$ Author for correspondence: <naharmunna@yahoo.com>. 
the literature. In such a situation, the objective of this study was to investigate the effects of ALA application on in vitro regulation of protocorm-like bodies (PLBs) of Cymbidium dayanum.

Approximately $5 \mathrm{~mm}$ long PLBs derived from proliferated meristem cultures of Cymbidium dayanum were cultured in modified MS (Shimasaki and Uemoto 1990). Such PLBs were used as explants. MS with $412.5 \mathrm{mg} / \mathrm{l}$ ammonium nitrate, $950 \mathrm{mg} / \mathrm{l}$ potassium nitrate, $20 \mathrm{~g} / \mathrm{l}$ sucrose and $2 \mathrm{~g} / \mathrm{l}$ Phytagel (Sigma) was adjusted to $\mathrm{pH} 5.5$ - 5.8 before autoclaving. Aminolevulinic acid (5 ALA- Cosmo oil Co., Ltd., Japan) at various concentrations (0, 0.1, 1 and $10 \mathrm{mg} / \mathrm{l})$ were added to culture media before sterilization. Jars of $250 \mathrm{ml}$ (UM culture bottle, As one, Japan) with plastic caps containing $30 \mathrm{ml}$ of medium were used for culture vessels. Five explants were put in each culture vessel and three culture vessels were used for each treatment. All cultures were maintained at $25^{\circ} \mathrm{C}$, a $16 \mathrm{hrs}$ photoperiod under white fluorescent tube (with irradiance of $54 \mu \mathrm{mol} \mathrm{m} / \mathrm{s}$ ) for 50 days. The data were analyzed using a one-way analysis variance (ANOVA) and differences between means were tested using Turkey's honestly significant different test $(\mathrm{p} \leq 0.05)$.

ALA significantly enhanced PLB and shoot formation within 50 days of culture of $C$. dayanum as shown in Table 1 . The maximum fresh weight (174.3 mg) of PLBs, the highest PLB formation rate $(87 \%)$, and the highest average number of PLBs was (6.6 PLBs/explant) were observed in explants cultured in the medium supplemented with $1 \mathrm{mg} / \mathrm{l}$ ALA, whereas in the control the fresh weight

Table 1. Effect of aminolevulinic acid (5-ALA) on PLB culture of Cymbidium dayanum after 50 days under white fluorescent tube.

\begin{tabular}{|c|c|c|c|c|c|c|c|}
\hline \multirow{2}{*}{$\begin{array}{l}\text { ALA } \\
(\mathrm{mg} / \mathrm{l})\end{array}$} & \multicolumn{3}{|c|}{ PLB } & \multicolumn{2}{|c|}{ Shoot } & \multicolumn{2}{|c|}{ Root } \\
\hline & No./explant & Rate & FW & No./explant & Rate & No./explant & Rate \\
\hline Control & $3.3 \pm 1.4 \mathrm{ab}$ & 53 & $109.2 \mathrm{a}$ & $0.5 \pm 0.8 b$ & 20 & $0.2 \pm 0.2 \mathrm{a}$ & 20 \\
\hline 0.1 & $4.5 \pm 1.8 \mathrm{ab}$ & 60 & $120.0 \mathrm{a}$ & $1.0 \pm 0.5 b$ & 47 & $0.7 \pm 0.4 a$ & 40 \\
\hline 1 & $6.6 \pm 1.4 a$ & 87 & $174.3 \mathrm{a}$ & $2.3 \pm 0.6 a$ & 73 & $1.1 \pm 0.5 a$ & 47 \\
\hline 10 & $2.0 \pm 0.6 b$ & 67 & $100.5 \mathrm{a}$ & $0.6 \pm 0.6 b$ & 53 & $0.5 \pm 0.4 a$ & 27 \\
\hline
\end{tabular}

*Value represents means \pm SE followed by the different letters show significant differences by Turkey HSD test $(\mathrm{p} \leq 0.05)$.

of PLBs was $109.2 \mathrm{mg}$, the rate of PLB formation being 53\%, with an average of 3.3 PLBs/explant after 50 days of culture (Fig. 1). The highest number of shoots (2.3 shoots/explant) and the highest shoot proliferation rate $(73 \%)$ were observed in the medium supplemented with $1 \mathrm{mg} / \mathrm{l}$ ALA compared to the control (0.5 
shoots/explant). In the application of 5-ALA, there was no significant difference between observed fresh weight and root formation. The highest root formation $(47 \%)$ and the highest number of roots (1.1 roots/explant) were obtained at $1 \mathrm{mg} / \mathrm{l}$ ALA, compared to the control where there was $20 \%$ root formation and the number of roots was 0.2 roots/explant.
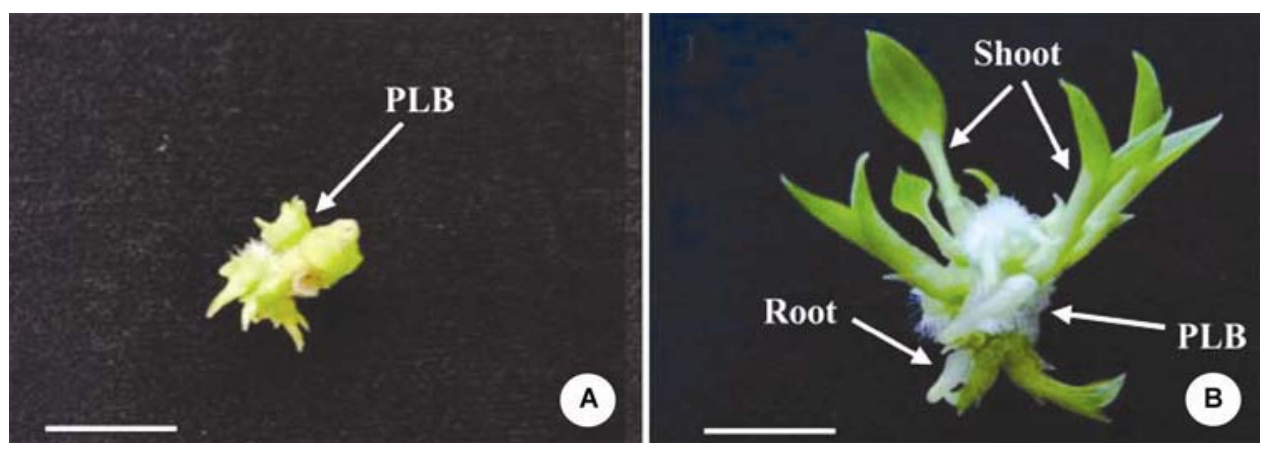

Fig. 1. The effect of 5-ALA with modified MS on organogenesis on PLB culture of Cymbidium dayanum in vitro. A: Control. B: $1 \mathrm{mg} / 1$ 5-ALA. $($ Bars $=10 \mathrm{~mm})$.

ALA appears to have a potential as a non-toxic endogenous substance for improving agricultural production. Studies have shown that ALA is not simply an intermediate step in the metabolism in plants. High concentration of exogenous ALA can be used as non-polluting, non-residual photosensitive herbicides; in low concentration, it can regulate plant growth and development, increase productivity and enhance plant resistance (Watanabe et al. 2000). Xu et al. (2010) suggested that the application of ALA at low concentrations can increase growth of Kudzu through increased photosynthetic rate. Nahar and Shimasaki (2014) reported that very low concentrations of ALA supplementation in culture media enhanced the formation of PLBs and shoots of Cymbidium species to the maximum. In Cymbidium insigne, 100\% new PLBs formation a higher number of PLBs (7.9 PLBs/explants) indicated that in the medium $1 \mathrm{mg} / 1$ ALA is the optimum concentration. Similarly, the present study confirmed that $1 \mathrm{mg} / \mathrm{l}$ ALA had significant effect on PLB, shoot and root formation of Cymbidium dayanum within 50 days of culture. In recent years, application of low concentrations of exogenous ALA has been found to promote plant growth, development and responses to environmental stresses (Roy and Vivekanandan 1998), such as crop productivity (Hotta et al. 1997), stress tolerance (Naeem et al. 2011, Liu et al. 2011). The results of such studies showed that the effect of ALA greatly depended on its concentration. 
The results of present study have shown that ALA has the ability to stimulate PLBs proliferation of Cymbidium in vitro. During 50 days of culture, there was no malformation observed in the regenerated shoots. The mechanisms by which ALA elicits plant growth not yet understood fully. A more detailed examination is required.

\section{References}

Hotta Y, Tanaka T, Takeuchi Y and Konnai M (1997) New physiological effects of 5aminolevulinic acid in plants: the increase of photosynthesis, chlorophyll content, and plant growth. Biosci. Biotech. Biochem. 61: 2025-2028.

Liu D, Pei ZF, Naeem MS, Ming DF, Liu HB, Khan F and Zhou WJ (2011) 5aminolevulinic acid activates antioxidative defense system and seedling growth in Brassica napus L. under water-deficit stress. J. Agron. Crop Sci. 197(4): 284-295.

Naeem MS, Rasheed M, Liu D, Jin ZL, Ming DF, Yoneyama K, Takeuchi Y and Zhou WJ (2011) 5-Aminolevulinic acid ameliorates salinity-induced metabolic, water-related and biochemical changes in Brassica napus L. Acta Physiol. Plant. 33:517-528.

Nahar SJ and Shimasaki K (2014) Application of 5-aminolevulinic acid on in vitro micropropagation of Cymbidium as a potential novel plant regulator. Environ. Control Biol. 52(3): 117-121.

Roy CB and Vivekanandan M (1998) Role of aminolevulinic acid in improving biomass production in Vigna catjung, $V$. mungo and V. radiate. Biol. Plant. 41: 211-215.

Shimasaki K and Uemoto S (1990) Micropropagation of a terrestrial Cymbidium species using rhizomes developed from seeds and pseudobulbs. Plant Cell Tissue Organ Cult. 22: 237-244.

Tanaka Y, Tanaka A and Tsuji H (1992) Stabilization of apoproteins of light-harvesting chlorophyll-a/b protein complex by feeding 5 aminolevulinic acid under intermittent illumination. Plant Physiol. Biochem. 30: 365-370.

Wang LJ, Jiang WB and Huang BJ (2004) Promotion of 5-aminolevulinic acid on photosynthesis of melon (Cucumis melo) seedlings under low light and chilling stress conditions. Physiol. Plant 121: 258-264.

Watanabe K, Tanaka T and Hotta $\mathbf{Y}$ (2000) Improving salt tolerance of cotton seedlings with 5-aminolevulinic acid. Plant Growth Regul. 32: 99-103.

Xu F, Zhu J, Cheng S, Zhang W and Wang Y (2010) Effect of 5-aminolevulinic acid on photosynthesis, yield, nutrition and medicinal values of kudzu (Pueraria phaseoloides). Tropical Grasslands 44: 260-265. 